\title{
Estratégias e processos participativos para o desenvolvimento local e regional na Baixada de Sepetiba, RJ
}

\author{
Strategies and participatory processes for local \\ and regional development in the Sepetiba Basin, RJ
}

Denise de Alcantara Pereira [I]

\begin{abstract}
Resumo
Este artigo apresenta a aplicação de ferramenta de cartografia social, a partir do olhar plural e participativo, para identificação e análise de fragilidades e potencialidades de território periférico na Baixada de Sepetiba, RJ, investigado a partir das transformações ocasionadas pelo crescimento econômico e pelos projetos de investimentos globais. Com base em conceitos de zonas opacas e luminosas, metropolização e desenvolvimento sustentável, a metodologia multitemática e transescalar analisa aspectos socioespaciais, integrando atores sociais e institucionais em uma reflexão conjunta e interativa e na produção de cenários prospectivos de desenvolvimento local. Valida-se a estratégia metodológica participativa para elaboração de diretrizes de planejamento do território ameaçado pela expansão metropolitana.
\end{abstract}

Palavras-chave: periferia metropolitana; cenários; cartografia social; análise SWOT; Baixada de Sepetiba.

\begin{abstract}
This article presents results of the application of a social cartography tool, based on a plural and participatory approach, to the identification and analysis of the weaknesses and potentials of a peripheral territory in the Sepetiba Basin, State of Rio de Janeiro. The area was investigated through the transformations caused by economic growth and global investment projects. Based on concepts of opaque and bright areas, metropolization and sustainable development, the multi-thematic and multiscale methodology analyses socio-spatial aspects, integrating social and institutional actors in a joint interactive reflection and in the production of prospective scenarios for local development. The article validates the participatory methodological strategy to develop guidelines for the planning of the territory threatened by metropolitan expansion.
\end{abstract}

Keywords: metropolitan periphery; scenarios; social cartography; SWOT analysis; Sepetiba Basin. 


\section{Introdução}

Os territórios até então opacos (Santos, 2006) da borda oeste metropolitana do Rio de Janeiro são trazidos à luz nas primeiras décadas do século XXI pelos impactos da expansão urbana e dos grandes projetos de investimentos (GPIs) alavancados pelo Estado e pela iniciativa privada (Oliveira et al., 2012). Os efeitos do avanço da economia global emergem em diversas áreas de infraestrutura: energética, logística, habitacional e urbana; entre 2007 e 2015, 1,9 trilhão de reais são investidos na construção de hidrelétricas, rodovias, pontes, viadutos, habitação de interesse social, com estímulo direto à construção civil e à indústria de beneficiamento. ${ }^{1}$ Geram-se emprego e renda e um período de bonança na economia brasileira (Silva, 2017). Nos anos que se seguem à implantação dos GPIs, as influências do crescimento econômico podem ser sentidas pela ampliação de postos de trabalho, provocando atração de novos contingentes populacionais nos municípios periféricos da Região Metropolitana do Rio de Janeiro (RMRJ). O quadro de expansão demográfica - da ordem de mais de $30 \%$ em Itaguaí e de quase 20\% em Seropédica entre 2000 a 2010 - não é precedida pela implementação ou melhorias na infraestrutura urbana nem pela ampliação da capacidade de absorver tal contingente populacional.

Dentre os feitos que mais influenciaram a expansão da RMRJ, destacam-se a rodovia logística Arco Metropolitano, que previa a interligação de dois polos estratégicos para a economia nacional: o complexo petroquímico, em Itaboraí, e o Porto de Itaguaí, na Baixada de Sepetiba. Ao atravessar oito municípios metropolitanos, o Arco trazia a promessa de alavancar as economias locais dos territórios por ele impactados, porém tal intenção não foi viabilizada em sua concepção, projeto e construção (Tângari, Rego e Montezuma, 2012).

Diante do cenário de expansão e globalização, as administrações municipais não acompanham o ritmo do crescimento urbano nem impõem limites à ocupação (Alcantara, 2016) dos espaços livres de edificações (Magnoli, 2006) predominantes nesses territórios e configurados como vasto estoque de terras a explorar. Desprovidos de um planejamento que respondesse de forma adequada à urgente questão da metropolização, apesar dos Planos Diretores elaborados sob essa premissa, os municípios da borda oeste metropolitana, especialmente Itaguaí e Seropédica, apresentam crescimento desordenado de suas manchas urbanas sem o acompanhamento das necessárias infraestruturas urbanas. Aprofundam-se, assim, as desigualdades sociais e os problemas ambientais e a desarticulação entre a governança pública e a participação social (Vianna, 2017).

Diante de tal conjuntura de incertezas e de grande complexidade de impactos da globalização sobre territórios periféricos, múltiplas possibilidades delineiam-se de modo a refletir sobre o avanço da metropolização sobre territórios periféricos com terras visadas para ocupação e investimentos especulativos. A prospecção de cenários apresenta-se como ferramenta estratégica para "lidar com possíveis situações futuras, a partir de uma lista limitada, porém estruturada, de opções de acontecimentos, permitindo que a organização analise como o ambiente se comporta e desenvolve ao longo do tempo e se prepara, antecipadamente, para um cenário que está se configurando" (Rubem e Moura, 2014). 0 planejamento por cenários, originado no 
planejamento estratégico corporativo, oferece a possibilidade de geração de intenções e orientações para futuros possíveis, prováveis ou desejáveis com base em decisões feitas no presente (Santos, 2013).

Nesse contexto, este artigo apresenta a aplicação de uma estratégia de prospectiva exploratória, de caráter participativo, cujo objetivo é fazer emergirem futuros possíveis aplicados à análise de questões socioespaciais do município de Seropédica, impactado de forma direta pelas pressões do irreversível processo de urbanização e expansão metropolitana fluminense.

Buscando avançar na questão do processo de planejamento participativo, de baixo para cima, a pesquisa agrega o conhecimento acadêmico desenvolvido ao longo de colaboração conjunta interinstitucional entre pesquisadores de áreas afins, que se debruçam sobre os impactos nas escalas regional e local da implantação do Arco Metropolitano (Tângari, Rego e Montezuma, 2012; Tângari, Rego e Montezuma, 2013). A aproximação da escala de estudo sobre o município de Seropédica tem por base a aplicação da metodologia estabelecida pela rede nacional de pesquisa Quapá/USP, que integra os grupos SELRJ-UFRJ e Gedur-UFRRJ, ${ }^{2}$ para a análise dos espaços livres de ocupação e das transformações oriundas do crescimento econômico sobre o território fragilizado social, política e ambientalmente.

Assim, o conjunto de estratégias e métodos consolidados na pesquisa sobre o Arco, durante a qual foram realizadas as Oficinas Locais Arquitetura da Paisagem (Isidoro; Alcantara e Tângari, 2011), e sobre Seropédica (Alcantara e Schueler, 2015; Alcantara, 2016) culminou com a realização, em 2015, da Oficina Participativa de Construção de Cenários
Prospectivos: Crescimento versus Desenvolvimento Sustentável na Baixada de Sepetiba. ${ }^{3}$

A Oficina Participativa representou um desdobramento previsto na pesquisa sobre o município de Seropédica desenvolvida pelo grupo Gedur. ${ }^{4}$ Configurada como atividade de extensão, a Oficina estabeleceu um fórum legítimo de discussão e de debate sobre os rumos do desenvolvimento local e buscou favorecer a prospecção e a construção de cenários que pudessem contribuir com a elaboração de diretrizes e parâmetros de planejamento, projeto e gestão municipal.

Sua principal meta foi gerar cenários de desenvolvimento e ocupação futura do território de Seropédica a partir do mapeamento participativo ou cartografia social (Acselrad, 2010). A atividade de extensão foi realizada em uma dinâmica coletiva e integrada na elaboração de mapas relacionados aos aspectos ambientais, socioeconômicos e urbanos, e matrizes inspiradas no método de análise Swot (Pickton e Wright, 1998), instigados pela reflexão, debate e desígnios sobre o território periférico.

A Oficina, realizada em três dias consecutivos, estruturou-se em torno de temáticas distintas que estabeleceram a organização das mesas-redondas, visitas de campo e dos grupos de trabalho (GTs). Os mapas e textos, elaborados pelos participantes no terceiro dia da Oficina, a partir das bases cartográficas produzidas pelo grupo de pesquisa, refletem cenários de desenvolvimento e evolução urbana e periurbana, bem como as expectativas positivas e/ou negativas sobre o território afetado pelas intervenções e projetos de investimento de caráter globalizante.

A prospecção de cenários futuros, a partir de processos participativos de cartografia 
social e da investigação multitemática e transescalar, pode auxiliar na elaboração de diretrizes de planejamento e na elaboração de políticas públicas de ordenamento urbano e territorial, sob a premissa do crescimento econômico aliado ao desenvolvimento equilibrado, justo e socioambientalmente responsável.

Este artigo está organizado em três partes: (1) contextualização multiescalar do objeto de estudo, o município de Seropédica e sua inserção metropolitana; (2) estrutura, organização e etapas de trabalho da Oficina Participativa; e (3) resultados apurados na prospecção de cenários. Nas considerações finais, verifica-se a validação da estratégia metodológica participativa de cenários prospectivos.

\section{Contextualização na escala metropolitana}

\begin{abstract}
A Região Metropolitana do Rio de Janeiro (RMRJ) é a segunda maior área metropolitana brasileira, seguindo apenas São Paulo, de acordo com dados do Censo 2010 (IBGE, 2019). Constituída em 1974 (lei complementar n. 20), após a fusão dos estados da Guanabara e Rio de Janeiro, é composta por vinte e dois municípios, dois deles, Cachoeiras de Macacu e Rio Bonito, anexados em 2013 em função da localização vizinha ao Comperj, em Itaboraí, na porção leste. Em fins de 2018, houve a inclusão de Petrópolis. ${ }^{5}$
\end{abstract}

A RMRJ constitui-se o segundo maior polo de riqueza nacional, onde se concentra $70 \%$ da força econômica do Estado, bem como grande parte dos bens e serviços produzidos nacionalmente, com um PIB de R\$404,37 biIhões. Abriga refinarias de petróleo, estaleiros, indústrias metalúrgicas, petroquímicas, siderúrgicas, têxteis, gráficas, farmacêuticas, de bebidas, cimenteiras, moveleiras e extrativistas, configurando o segundo maior polo industrial do País. Nas últimas décadas, passou por uma nítida transformação em seu perfil econômico, adquirindo matizes de um grande polo nacional de serviços e negócios até 2013 , refletindo o período de pujança econômica brasileira (Silva, 2017).

A densidade demográfica atinge 1.725,82 hab/ $/ \mathrm{km}^{2}$, porém a distribuição da população, não homogênea, ora se define de alto adensamento, ora de rarefeita ocupação, esta principalmente em suas bordas. A proporção populacional que se desloca para trabalhar e estudar em localidades fora de seu local de residência comprova o alto grau de integração entre os municípios que a compõem, de acordo com os indicadores de evolução demográfica, fluxos de deslocamentos pendulares, densidade e características ocupacionais (Observatório das Metrópoles, 2005).

Nesse sentido, inaugurado em 2014, 0 Arco Metropolitano do Rio de Janeiro, rodovia logística financiada pelo PAC Federal com o fim de interligar dois importantes polos econômicos, o Comperj, em Itaboraí, e o Porto de Itaguaí, na Baía de Sepetiba, configura-se um catalisador do crescimento econômico e demográfico, especialmente nos municípios que ele atravessa e influencia, como é o caso de Itaguaí e Seropédica (Tângari, Rego e Montezuma, 2012).

Na primeira década do século vinte e um, o município de Itaguaí apresentou um crescimento populacional da ordem 33,03\%, enquanto Seropédica, de 19,81\%, o terceiro e quarto maiores no ranking metropolitano. A tendência de crescimento é ainda maior pela 
Tabela 1 - Aspectos socioeconômicos e demográficos nos municípios da borda oeste metropolitana em relação ao Rio de Janeiro e à RMRJ - 2019

\begin{tabular}{|c|c|c|c|c|c|c|c|c|}
\hline Município & Área $\mathbf{k m}^{2}$ & Pop 2000 & Pop 2010 & $\begin{array}{c}\text { Pop. estim. } \\
2018\end{array}$ & $\begin{array}{c}\text { Cresc. Demog. } \\
\text { 2000-18 }\end{array}$ & $\begin{array}{c}\text { Densid. Demog. } \\
\text { hab. } / \mathrm{km}^{2}\end{array}$ & $\begin{array}{c}\text { PIB } \\
\text { per Capita }\end{array}$ & IDH \\
\hline Itaguaí & 273,41 & 82.003 & 109.091 & 125.913 & $34,9 \%$ & 395,45 & $65.107,78$ & 0,715 \\
\hline Japeri & 81,697 & 83.278 & 95.492 & 103.960 & $20,0 \%$ & $1.166,37$ & $12.874,11$ & 0,659 \\
\hline Queimados & 73,921 & 121.993 & 137.962 & 149.265 & $19,9 \%$ & $1.822,60$ & $32.314,25$ & 0,732 \\
\hline Seropédica & 283,79 & 65.260 & 78.186 & 86.743 & $24,8 \%$ & 275,53 & $24.602,97$ & 0,713 \\
\hline Rio de Janeiro & $1.200,18$ & 5.857 .904 & 6.320 .446 & 6.688 .927 & $12,5 \%$ & $5.573,28$ & $50.690,82$ & 0,799 \\
\hline RMRJ* & $7.535,78$ & - & - & 13005430 & - & $1.725,82$ & $33.856,54$ & 0,771 \\
\hline
\end{tabular}

$\left({ }^{*}\right)$ as várias alterações de inclusão e exclusão de municípios nos últimos anos impedem uma definição precisa. Consideramos a configuração atual de 2018, constando 22 municípios, com a recente inclusão de Petrópolis.

Fonte: IBGE (2019) Cidades@ - Instituto Brasileiro de Geografia e Estatística. Disponível em https://cidades.ibge.gov. br/brasil/rj/seropedica/panorama. Acesso em: 24 set 2019.

estimativa de $250 \%$ de aumento populacional até 2025 em Seropédica (Nova Cedae, 2015), e os dados oficiais indicam uma tendência de expansão demográfica que diz respeito a toda a borda oeste metropolitana (ver Tabela 1).

A investigação na macroescala indica contrastes e dualidades em toda a borda oeste metropolitana, considerada como área de expansão com vocação industrial e logística da RMRJ (Governo do Estado, s/d).

O município de Seropédica, foco desta análise, apresenta vasto estoque de terras planas de baixo custo, viáveis para ocupação, o que implica grande interesse político pelo que isso representa em termos de retorno em taxas e impostos municipais. Por isso, passa a ser alvo de investimentos públicos e privados, de caráter especulativo em vários segmentos: habitação social; instalações industriais; condomínios logísticos; atividades extrativistas minerais; entre outros. Cabe mencionar que tais usos acabam por se sobrepor às atividades agrícolas e agropastoris de pequena escala, principalmente a agricultura familiar e orgânica, que, sem apoio governamental e sem fortes laços associativos, acabam perdendo seu território para o capital (Vianna, 2017). Historicamente, os modelos neoliberais de ocupação e urbanização implantados nos espaços metropolitanos fluminenses, que privilegiam o núcleo com investimentos e benesses e descarta a pobreza e os usos indesejados na periferia (Maricato, 2001), afetam diretamente a qualidade da paisagem e se refletem negativamente no sistema de espaços livres urbanos e periurbanos (Tângari; Schlee; Andrade, 2009).

Nesse sentido, os Grandes Projetos de Investimentos (GPIs) (Oliveira et al., 2012) que se vinculam a interesses globais de desenvolvimento econômico, muitas vezes passam ao largo de questões locais relativas aos impactos por eles gerados (Acselrad, 2010). Considerados setores de integração de áreas metropolitanas representados por obras de infraestrutura, tais investimentos tendem a ser implementados em grande escala para promover 
a expansão e a ocupação dos espaços livres perimetropolitanos, pouco visíveis e com baixa densidade demográfica e construtiva, ou seja, as zonas opacas (Santos, 2006).

O Arco Metropolitano torna-se um ícone dos GPIs. A mesma ideologia desenvolvimentista (Cardoso e Araújo, 2012) que resultou em sua implantação ocasiona transformações na paisagem e no território. Fundado nas esferas federal e estadual, o Plano Diretor do Arco Metropolitano torna as gestões públicas municipais responsáveis pela promoção de infraestruturas econômicas e sociais próprias para potencializar as economias locais (Brandão, 2012), sem que sejam estabelecidos ou garantidos os critérios e as ações para a mitigação/ compensação dos impactos socioambientais dele provenientes. Pode se perceber claramente a "perspectiva predominantemente economicista na análise dos impactos propagados pelo Arco Metropolitano, onde se destacam quase exclusivamente questões de logística [...] e de economia" (ibid., p. 97). Perfazendo um traçado por áreas de baixa densidade de ocupação ou urbanização, sua inserção não se dá por mero acaso, pois questões fundiárias são mais facilmente contornáveis, facilitando as desapropriações dos espaços livres predominantes no território (Tângari et al., 2012).

A lógica de mercado impetrada pelos segmentos mais conservadores das esferas políticas e econômicas apoiam-se no discurso da sustentabilidade e no marketing corporativo por meio de simulacros e novas divisas de capitais sem, de fato, ater-se na função social da propriedade e no direito à cidade, especialmente em relação aos mais pobres (Kzure-Cerquera, 2014). A produção de planos e projetos urbanos demanda a interlocução contínua entre campos do saber distintos, sendo essa uma das alternativas para que se possam compreender a heterogeneidade, a diversidade e a complexidade das dinâmicas sociais presentes nos mais diversos estratos populacionais. O local é confrontado com o global e as territorialidades enfraquecem, bem como se desloca o sentido de pertencimento a um espaço geográfico ou a um grupo sociocultural distinto (Sack, 2011). Por isso, os cenários esboçados para intervenções urbanas devem minimizar ou eliminar barreiras sociais que estigmatizam, segregam e confinam. As ações urbanas devem ser precedidas de uma “avaliação baseada na percepção e apreensão ambiental, bem como em critérios qualiquantitativos" (Kzure-Cerquera, 2014, p. 60). Acreditamos que o planejamento urbano deva privilegiar práticas inclusivas e de interação entre o indivíduo e a cidade, garantindo melhor qualidade nas relações sociais e ambientais.

Torna-se essencial, portanto, o fortalecimento das conexões entre as distintas dimensões espaço-temporais da cidade e do território, em associação com a mobilização social, a partir da criação de instrumentos, procedimentos e parâmetros urbanísticos estabelecidos sob a premissa democrática. Nesse sentido, a atuação de planejadores não deve se limitar apenas a pensar soluções objetivas e impositivas, de cima para baixo, para problemas identificados em estudos e diagnósticos elaborados a distância. De modo a possibilitar uma mudança nesse quadro, buscamos intermediar as articulações entre as ações públicas e a população, atuando na esfera política. Sob essa perspectiva, um dos papéis da ferramenta Oficina Participativa aqui apresentada foi o de catalisar e promover tal articulação, promovendo a criação de um espaço de discussão coletiva e de inclusão social. 
A condição locacional estratégica de Seropédica favorece seu crescimento econômico, especialmente pela proximidade do Arco e de importantes centros consumidores e produtores, além de oferecer extensões de terra potencialmente urbanizáveis e planas. Entretanto, para que haja um desenvolvimento equilibrado e sustentável há que se levar em consideração o suporte geográfico - representado pelo solo, pela topografia, pela estrutura hídrica, pela cobertura vegetal, pelas áreas habitadas - no qual as intervenções e as transformações possam ocorrer sem colocar em risco seu equilíbrio ambiental e social. 0 espaço ocupado de forma rarefeita é, por um lado, fragmentado por eixos viários e carente de infraestrutura (urbana e de saneamento); e possui, por outro lado, importantes recursos hídricos, minerais, ambientais e sociais que vêm sendo ameaçados pelo avanço da urbanização especulativa, tais como o rio Guandu, o aquífero Piranema e a Flona Mario Xavier (Alcantara e Schueler, 2015).

Estudos e análises de planos diretores municipais realizados pelo Observatório das Metrópoles (Santos Junior e Montandon, 2011; Rego, 2011), inclusive em relação ao objeto deste artigo, tornam óbvio o limitado poder da gestão municipal para mudar os rumos da expansão capitalista, demonstrando conflitos e contradições gerados pela força do desenvolvimento econômico sobre uma região estratégica em relação à metrópole, mas também frágil ambiental e socialmente.

A função social da propriedade urbana deve ser definida pelo Plano Diretor no sentido de garantir acesso à terra urbanizada e o direito à moradia a todos, "bem como de implementar uma gestão democrática e participativa" (Santos Junior e Montandon, 2011, pp. 14-15). Deve-se buscar, assim, o fortalecimento da gestão democrática, com vistas à inclusão social, à regularização fundiária e à redução das desigualdades, da segregação, dos conflitos socioespaciais e da degradação ambiental. Assim, assumimos um posicionamento de oposição à assimetria entre centro e periferia, tão visível e comum nas cidades brasileiras, nas quais se verificam investimentos públicos, regulação urbanística e melhorias infraestruturais no ambiente urbano, enquanto, nas periferias, prevalecem a falta de investimentos e a perpetuação das precariedades e das desigualdades (Maricato, 2001).

Com a intensificação da ocupação industrial e de instalações de condomínios logísticos ao longo do Arco, da via Dutra e da BR-465, rodovias que fragmentam o território de Seropédica, a qualidade ambiental fica ameaçada e comprometida, risco que paira também sobre as margens dos rios, as encostas e as poucas áreas florestadas. São estas as áreas que acabam por abrigar assentamentos irregulares, ocupados precariamente por grupos sociais atraídos pela oferta de empregos temporários de baixa qualificação. Não se verifica a preocupação de planejamento para o crescimento previsto, seja em termos habitacionais, seja em termos de saneamento básico, transporte público, fornecimento de água e energia, entre outros serviços infraestruturais necessários ao espaço urbano de qualidade (Alcantara, 2016).

O Plano Diretor Participativo do município emancipado em 1995 de Itaguaí (Seropédica, 2006) possui um discurso inclusivo e sustentável. Entretanto, inconsistências e lacunas estão presentes, tais como as redundâncias dos artigos 20 e 3 , ambos tratando de objetivos; o art. 4으, que indica "meios e ações" para a execução dos objetivos, que não 
os sistematiza e operacionaliza de forma clara. Dos 23 artigos sobre planejamento urbano, somente o 9ㅇ apresenta diretrizes genéricas e vagas, sem especificar a estratégia de desenvolvimento. 0 macrozoneamento divide o município em três áreas: urbana, de expansão urbana e rural, em um mapa preliminar, sem coordenadas geográficas, que indica por manchas os usos do solo em cores que confundem o leitor. Ao confrontar com os atuais usos, observa-se a nítida sobreposição entre uso existente e proposto, configurando apenas o estabelecimento do que já existe. Outros 22 artigos abordam questões urbanas, como a mobilidade, indicando um anel rodoviário (não o Arco) "a ser construído brevemente" que interligaria as rodovias que atravessam o município, bem como a implantação de um Terminal Rodoviário de Passageiros; nenhum dos dois saiu do papel. Sobre habitação de interesse social, o art. 350 não estabelece prazos ou metas para a ampliação e melhoria do atendimento habitacional de qualidade, ficando apenas as boas intenções. Outras temáticas urbanas, como o meio ambiente e o saneamento ambiental, aparecem também como intenções, sem detaIhamento de ações. Dentre várias outras questões prementes do Plano Diretor Municipal PDM, verifica-se que não há qualquer menção à preexistência da Universidade Federal Rural do Rio de Janeiro ou a ações integradoras com esse importante ente federal presente no município (Alcantara e Schueler, 2015).

Para além das limitações de planejamento, as potencialidades da Baixada de Sepetiba em tornar-se um polo logístico e industrial são ditadas tanto pelo avanço do capital global, quanto por sua posição geográfica privilegiada e por sua topografia plana. 0 estabelecimento de ações para mitigar, minimizar ou mesmo evitar a destruição de seus recursos naturais demanda o entendimento sistêmico, tanto dos aspectos relacionados ao crescimento econômico, ao desenvolvimento e à economia regulatória (Harvey, 2011), quanto aos princípios socioambientais e culturais, que envolvem migração e movimentos sociais, pegada ecológica, biofilia, entre outros (Forman, 2008). Considerando o suporte geográfico da Baixada de Sepetiba como recorte macro ou regional, aplica-se o conceito de ecologia da paisagem para a análise e estudo dessa porção do mosaico territorial fluminense, mais abrangente, e a escala micro, ou local, que integra os padrões espaciais da escala do território seropediquence.

Quanto ao recorte macro, ou da bacia hidrográfica, a análise da estrutura hídrica faz parte de um estudo socioambiental maior que integra a identificação de unidades morfo-territoriais e a categorização dos sistemas de espaços livres de edificações (Tângari; Schlee e Andrade, 2009). O rio Guandu e o aquífero Piranema analisados nessa escala e configuram determinantes na questão do abastecimento de água em nível metropolitano. Ambos se encontram ameaçados em função das atividades extrativistas e mineradoras e da expansão urbana e logística (Alcantara e Schueler, 2015).

Enfatizam-se as condicionantes geobiofísicas relativas ao solo, ao clima, à topografia, à cobertura vegetal, à geomorfologia e mesmo às manchas de ocupação humana, pois tais elementos determinam a paisagem que dá suporte às ações antrópicas e deve ser o ponto de partida de qualquer plano ou projeto, seja para o desenvolvimento econômico, seja para a proteção ou preservação do ambiente natural (Mcharg, 1992). Problemas ambientais ameaçam a produção hídrica do rio Guandu em função da expansão urbana e ocupação do 
território e da poluição proveniente de seus afluentes; a falta de infraestrutura, de drenagem pluvial e os alagamentos na planície aluvionar ocasionam o carregamento de poluentes para os cursos d'água pela capilaridade natural do solo arenoso; áreas de preservação permanente (APPs) são ameaçadas, tanto pelo poder da "destruição criativa" da terra (Harvey, 2011), quanto pela ingerência pública sobre a ocupação irregular do ambiente fragilizado; a existência da Unidade de Conservação representada pela Floresta Nacional Mario Xavier Filho (Flona), único fragmento florestado de mata atlântica no município e habitat de um anfíbio raro (Physalaemus soaresi), não impediu que o traçado do Arco Metropolitano a dividisse em duas partes, fragmentando a floresta, bem como todo o território, sem promover a integração intramunicipal.
Outros problemas ambientais diretos são causados pela extração de areia ao longo da Reta de Piranema (RJ-099), que conecta os municípios de Itaguaí e Seropédica. 0 maior polo de extração mineral em ambiente de cava submersa do estado do Rio de Janeiro abastece a indústria da construção civil da RMRJ. $O$ descontrole dessa atividade e a falta de fiscalização ocasionam danos ambientais irreversíveis, descaracterizam a paisagem e contaminam o superficial e frágil lençol freático, impactando o aquífero Piranema, cuja água aflora nas cavas de areia abandonadas após o esgotamento do sítio explorado (Figura 1).

A área territorial de Seropédica contabiliza $283,79 \mathrm{~km}^{2}$, e mais de $85 \%$ dessa e áreas se constitui por espaços livres de edificações (Alcantara, 2016) em planície situada entre as escarpas da Serra do Mar e o rio Guandu. Com

Figura 1 - Cavas de areia abandonadas representam um dano ambiental irreversível na Baixada de Sepetiba

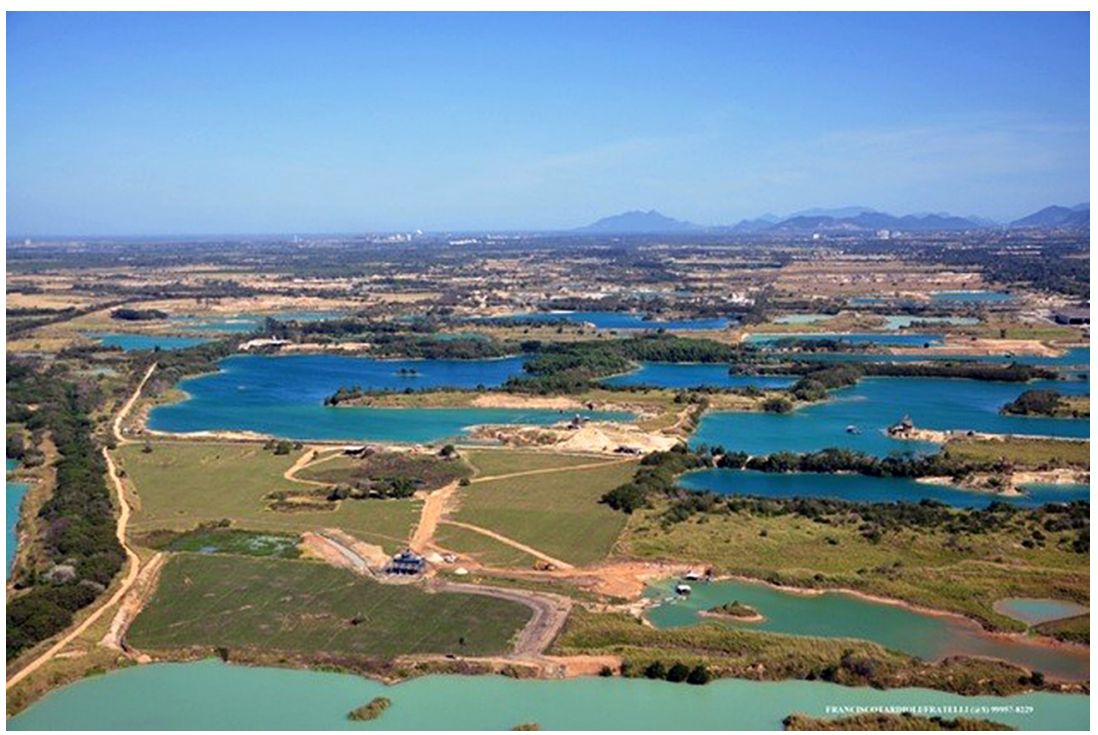

Foto: Francisco Tardiolli, acervo Gedur, 2015. 
um dos menores índices de densidade demográfica $\left(275,53 \mathrm{~h} / \mathrm{km}^{2}\right)$ e $21,62 \%$ de população rural (IBGE, 2010), seu território, com apenas $19,7 \%$ de vias urbanizadas (IBGE, 2019), é considerado área urbana na totalidade, onerando produtores rurais com taxas e impostos, mesmo em áreas não urbanizadas.

Em termos socioeconômicos, o PIB per capita de $\mathrm{R} \$ 24.602,97$ é $28 \%$ menor daquele aferido na RMRJ (R\$33.856,54) (IBGE, 2019) e o IDHM, de 0,713 , é bem inferior ao do núcleo metropolitano que atinge 0,799. O IDHM de Seropédica, alto de acordo com o PNUD (2013), pode ser explicado pela presença da Universidade Rural em seu território. Tal presença não representa, entretanto, redução das carências infraestruturais, de saneamento, de mobilidade, de urbanização e habitacionais, tampouco a expansão urbana em torno da universidade foi benéfica social ou culturalmente, permanecendo como uma "ilha" de racionalidade e conhecimento, em um território desarticulado e carente.

Os diversos municípios metropolitanos emancipados na década de 1990 - Belford Roxo, Guapimirim, Queimados, Japeri, Tanguá, Mesquita, além de Seropédica - têm em comum um reduzido desempenho econômico e um alto grau de precariedade nas condições de vida e bem-estar dos seus habitantes e na capacidade de gestão pública local. Isso se revela ainda mais preocupante pelo nível de renda mensal per capita nesses municípios, em torno de $R \$ 511,00$ (baixo em relação ao do Estado que atingia, em 2010, R\$991,00), sendo 36\% de pobres (considerando-se a linha de pobreza a metade do salário mínimo em 2010, R\$255,00) (Sebrae, 2015), obrigando a população pobre a lutar pela sobrevivência, sem dispor de tempo, desperdiçado no movimento pendular diário, ou energia para pressionar a gestão pública por melhores condições de vida. Mesmo com o aumento da renda per capita de $28,39 \%$ entre 2000 e 2010 (de $\mathrm{R} \$ 471,07$ para $\mathrm{R} \$ 604,82$ ), o índice de ocupação formal e a redução da informalidade, o TCE-RJ (2013) caracteriza o município com pouca autonomia econômica, com o setor terciário (comércio e os serviços) o mais ativo, apresentando uma parcela majoritária de microempresas (91,6\%) (Sebrae, 2015). O setor primário, de pouca influência no PIB local, tem na extração mineral uma importante atividade que fomenta o desenvolvimento em nível regional e metropolitano. 0 Arranjo Produtivo Local Areias de Piranema fornece $90 \%$ da areia utilizada na construção civil da RMRJ, apesar dos irreversíveis danos ambientais acima mencionados (Alcantara, 2016).

\section{Estrutura da Oficina Participativa}

A partir da investigação e das descobertas da realidade urbana e periurbana de Seropédica, o Gedur promoveu a realização da Oficina Participativa de Construção de Cenários Prospectivos: Crescimento versus Desenvolvimento Sustentável na Baixada de Sepetiba. 0 objetivo principal foi contribuir com a reflexão e a produção de cartografia social sobre a paisagem urbana e o território, resultantes de diálogo entre academia, agentes institucionais de planejamento e gestão e atores sociais, que vivenciam e se apropriam cotidianamente dos espaços urbanos e periurbanos da porção oeste da metrópole que se expande.

A metodologia de cenários, desenvolvida inicialmente para ser utilizada como 
instrumento de apoio à decisão no planejamento estratégico corporativo (Schoemaker, 1995), pode ser aplicada para definir rumos políticos, socioeconômicos ou em processos de planejamento urbano. Integra criatividade e colaboração entre agentes internos e externos diversos, a partir do princípio básico de multiplicidades e incertezas em direção a um futuro possível, imaginável ou desejável. De acordo com Rubem e Moura (2014), busca identificar possibilidades de mudanças de estratégia, por vezes ignoradas por outros métodos, organizando-as em narrativas mais simplificadas e sem um excessivo número de dados, sendo usada para desenhar desdobramentos futuros. Sua aplicação na atividade da Oficina Participativa favoreceu, principalmente, a elaboração de cenários de ocupação e uso do solo urbano e periurbano em um processo qualitativo, participativo e de "baixo para cima", integrando atores e agentes locais no diagnóstico e nas recomendações para a tomada de decisão pela gestão municipal.

Com expressivo número de inscritos para uma oficina de caráter local (cerca de 50 pessoas), a Oficina realizada em 2015, durante três dias, integrou pesquisadores, docentes e discentes de graduação e pós-graduação de áreas afins: arquitetura, urbanismo, paisagismo, educação, geografia, economia, sociologia; delegados das instâncias administrativas e órgãos públicos locais; e moradores. A oficina promoveu não apenas a consolidação da rede de grupos acadêmicos interdisciplinares que trabalhavam temas de pesquisa afins, como também estabeleceu um novo canal de diálogo entre a universidade, a governança pública e a participação social.

A estrutura da oficina inspirou-se nas primeiras cinco etapas do método de
Schoemaker: 1) definição de escopo (impactos do Arco na RMRJ); 2) identificação de agentes (academia; agentes públicos e atores sociais; 3) identificação de tendências básicas; 4) incertezas-chave; e 5) verificação de consistência e plausibilidade (ibid.).

Cabe enfatizar que, nas etapas 3 a 5 , foi de fundamental importância o arcabouço metodológico desenvolvido pelo SELRJ (Tângari, Rego e Montezuma, 2012) na investigação do Arco Metropolitano. 0 método de Oficinas Locais (Isidoro; Alcantara e Tângari, 2011) foi apropriado e adaptado para essa atividade, mantendo a estrutura com base nos aspectos temáticos e transescalares do sistema de espaços livres de edificação, a saber: desenvolvimento econômico e gestão; transportes e redes; centralidades urbanas; e paisagem e planejamento.

Na preparação da oficina, a elaboração dos mapas e bases cartográficas deu suporte à atividade prática de construção de cenários prospectivos. Com o apoio da equipe de pesquisa, foram coletados dados estatísticos e realizadas pesquisas de campo para levantamento in loco de aspectos físico-espaciais, complementados por bases cadastrais e aerofotogramétricas disponibilizadas por órgãos oficiais. ${ }^{6} \mathrm{~A}$ cartografia básica, gerada em diversas escalas, atualizou a análise dos processos de transformação em curso no território. A discussão conceitual e metodológica constante entre os colaboradores objetivou balizar a pesquisa sob um arcabouço teórico consistente, que atendesse ao principal objetivo de favorecer a construção de cenários de modo coletivo. Assim, os estágios anteriores à realização da Oficina passaram pelo escrutínio e consenso dos pesquisadores envolvidos, desde o entendimento dos 
conceitos usados - metropolização (Maricato, 2001), sistemas de espaços livres (Tângari; Schlee e Andrade, 2009), cartografia social (Acselrad, 2010) - ao estabelecimento de uma mesma linguagem gráfica clara e informativa dos aspectos territoriais, morfológicos e legislativos, sem a pretensão de esgotar cada um desses aspectos nos mapas-base preparados como suporte dos grupos de trabalho na Oficina.

Os mapas-base foram elaborados na escala meso (setorial, representativa dos municípios), sendo gerados quatro mapas de sistematização dos aspectos levantados relativos a: (a) suporte territorial - topografia, redes, transportes e hidrografia; (b) aspectos legislativos - macrozoneamento previsto no PDM sobreposto às manchas de ocupação urbana; (c) unidades de paisagem ou morfo-territoriais (Silva; Lima e Magalhães, 2015) - identificação de manchas similares de suporte físico, padrão de drenagem, cobertura vegetal e mancha urbana/padrões de ocupação; e (d) mapa-síntese da paisagem, com os elementos estruturadores do território (Figuras 2 a 5).

Gerados a partir de bases oficiais e utilizando geotecnologias de acesso livre e aplicativos de georreferenciamento (Google Earth, QGis), os mapas possibilitaram a delimitação

Figuras 2 e 3 - esquerda: mapa de redes viárias e aspectos geofísicos de Seropédica; direita: mapa de zoneamento e sobreposição de núcleos urbanos
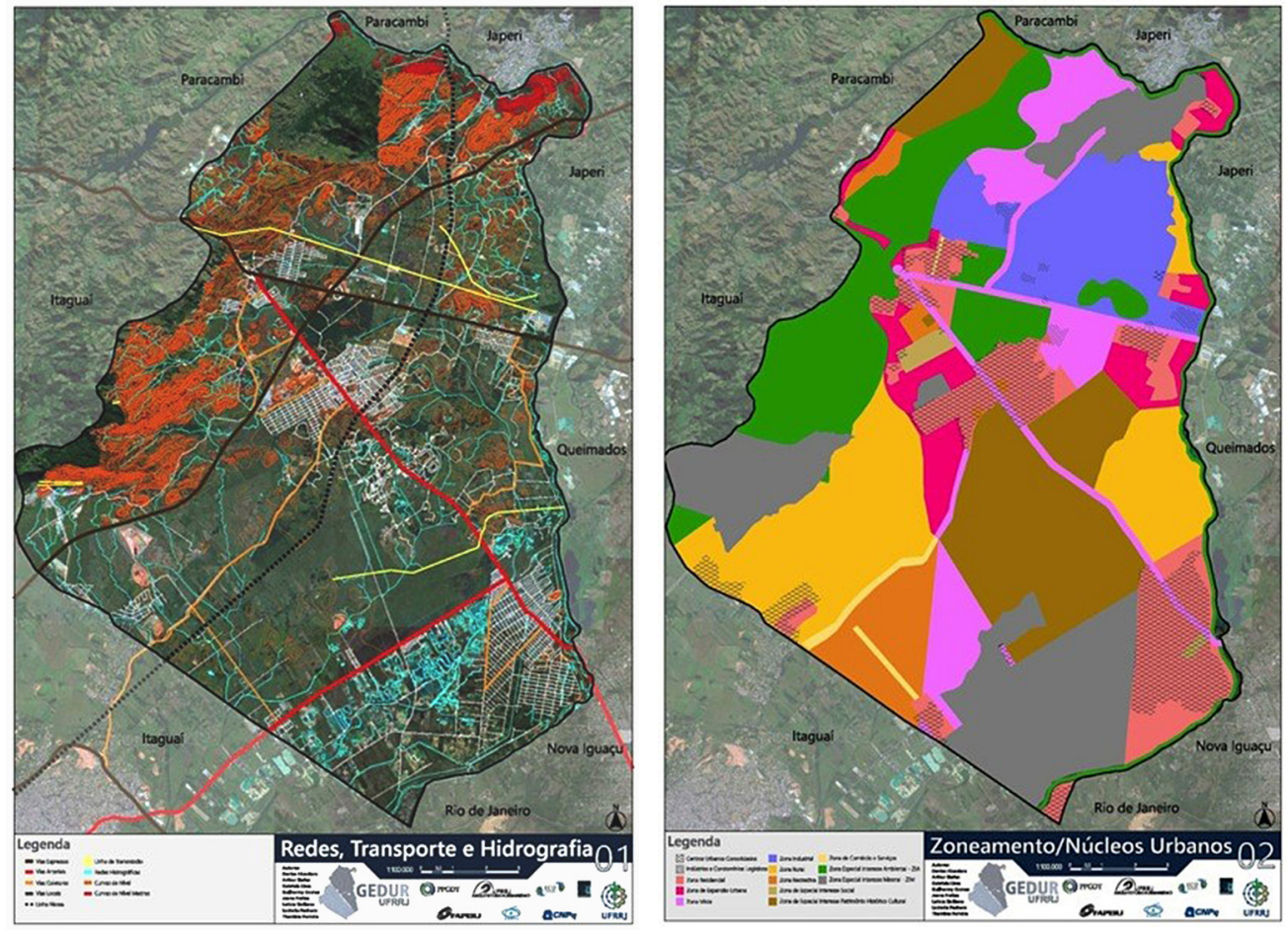

Elaborados por Arthur S. B. Santos. Fonte: acervo Gedur, 2015. 
Figuras 4 e 5 - esquerda: mapa com identificação de unidades morfo-territoriais; direita: mapa-síntese sobre a paisagem de Seropédica
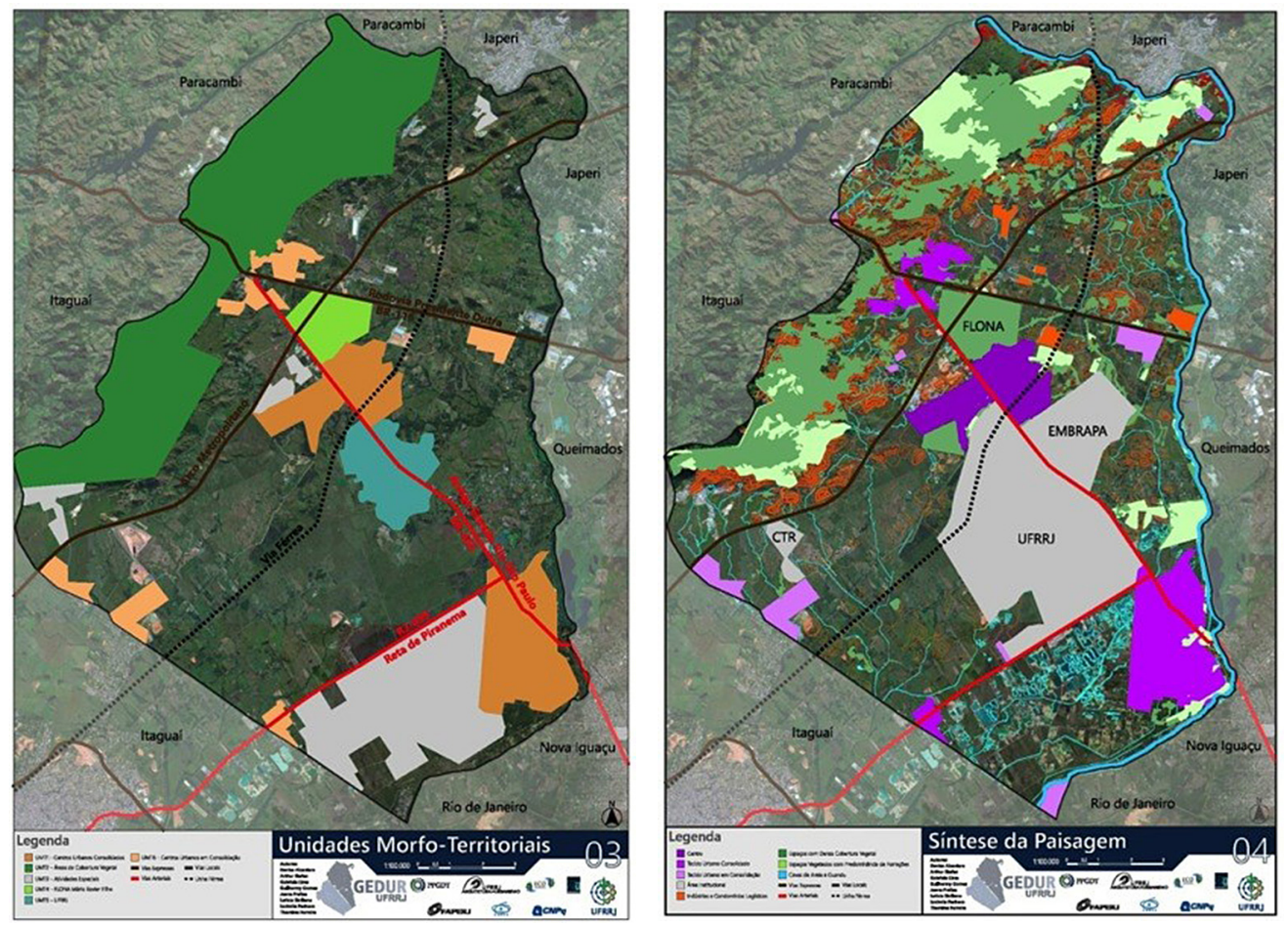

Elaborados por Arthur S. B. Santos. Fonte: acervo Gedur, 2015.

dos espaços livres de edificações existentes e a categorização de uso e apropriação, das condições da cobertura vegetal, topográficas e morfológicas municipais. Permitiram, ainda, a delimitação das manchas de ocupação urbana consolidada e em consolidação, a identificação dos vetores de expansão e as principais redes hidroviárias existentes. Sua sobreposição esclareceu aspectos concordantes, discordantes, conflitos e contradições, entre os elementos estruturadores da paisagem e os aspectos morfo-territoriais.
A dinâmica dos trabalhos foi estabelecida em torno das quatro temáticas estabelecidas pelo SELRJ, e a estrutura da Oficina foi dividida em três sessões distintas: palestras e mesas-redondas, visitas técnicas e grupos de trabalho. As primeiras duas sessões foram dedicadas ao debate de temáticas envolvendo as diversas escalas de análise do território. ${ }^{7} \mathrm{~A}$ escala na perspectiva da expansão urbana e periurbana na América Latina, com a apresentação do conceito de cidade mestiça, foi apresentado por Ciccolella (2014). A escala da região 
metropolitana e dos impactos da metropolização foi debatida por Souza (2012), Rego (2011) e Kzure-Cerquera (2014). Na perspectiva da baixada de Sepetiba, ofereceram contribuições Villela (2013), abordando o controle social e as formas de produção no desenvolvimento local; e Montezuma (Montezuma e Cintra, 2012), que discorreu sobre a questão do suporte geobiofísico e os problemas ambientais inerentes à região. Na experiência participativa em relação a Planos Diretores e ações integradas, contribuíram Silva (Silva; Lima e Magalhães, 2015) e Tângari (Tângari; Rego e Montezuma, 2012). A discussão propiciou um entendimento das transformações em curso e o compartilhamento das experiências interinstitucionais relacionadas à temática da Oficina, em preparação conceitual para a terceira sessão: a construção coletiva de cenários prospectivos.

A visita técnica, realizada por via terrestre na manhã do segundo dia, percorreu, em ônibus institucional da UFRRJ, diversas partes do município, perfazendo um percurso preestabelecido: UFRRJ - Rodovia BR-465 (antiga Rio-São Paulo); Arco Metropolitano, desde a via Dutra, passando pela Flona, mineradoras, centro de tratamento de resíduos Santa Rosa; estrada do Chaperó (conjuntos do PMCMV); estrada Santa Rosa; Reta de Piranema e areais; bairro Incra e estrada do Guandu; e retorno à UFRRJ. Uma ficha de registro foi disponibilizada para que os participantes inserissem suas impressões e os dados coletados. Visualizar e experienciar in loco os aspectos socioambientais tornam-se fundamentais, no sentido de sensibilizar os participantes quanto a possíveis propostas mitigadoras ou compensatórias durante a atividade prática realizada após a visita técnica.

\section{Construção de cenários prospectivos}

No terceiro dia, ocorreu a sessão mais importante da Oficina: a prospecção coletiva de cenários e visões de futuro para a região. Os participantes foram divididos em Grupos de Trabalho (GTs) sob as temáticas preestabelecidas: (1) desenvolvimento econômico e gestão; (2) transportes e redes; (3) centralidades urbanas; e (4) paisagem e planejamento.

A construção de cenários na Oficina Participativa inspirou-se na fundamental contribuição de Acselrad (2010) sobre cartografia social e teve como base o método de análise diagnóstica Swot (Pickton e Wright, 1998), nacionalmente designada Fofa. ${ }^{8}$ Tal método não deve ser considerado estático e conclusivo, mas auxiliar na estruturação de um planejamento responsivo às questões e aos problemas identificados.

A elaboração coletiva de cartografias sociais - mapas, croquis e textos dentro das temáticas específicas -, pelos GTs, foi acompanhada da elaboração de uma matriz estruturada a partir do método analítico Swot e da metodologia de Schoemaker (1995). Na matriz foram identificadas forças, oportunidades, fraquezas e ameaças, e definidas algumas estratégias para resolver ou mitigar os problemas identificados, verificar as hipóteses e prever desdobramentos. A adaptação da metodologia Swot, nesse caso voltada a uma ação participativa, estimulou o debate e a reflexão sobre potencialidades, conflitos e fragilidades territoriais. Aspectos positivos e negativos puderam ser identificados na construção dos cenários e confrontados com a análise realizada previamente do PDM. 
Utilizando a matriz Swot como meio de elencar cada um dos fatores por tema abordado, os membros dos GTs elaboraram coletivamente mapas, espacializando os pontos discutidos. As conclusões foram alvo de complementos e debates com a participação de todos. A dinâmica gerou, com o material e os dados coletados, uma rica fonte para a proposição de diretrizes de planejamento do uso e ocupação do solo de Seropédica.

Em seguida, são apresentados alguns dos mapas elaborados durante a Oficina e posteriormente digitalizados pelo grupo de pesquisa, bem como as matrizes Swot correspondentes a cada GT (Figuras 6 a 13 e Quadros 1 a 4).

As estratégias elencadas nos domínios selecionados pelos GTs durante a Oficina representaram o primeiro esboço da construção de cenários e visões positivos e negativos em relação à expansão metropolitana e aos impactos gerados em nível local, conforme indicados nas matrizes acima.

De acordo com os dados analisados e produzidos na pesquisa e na Oficina Participativa, são grandes os conflitos e as contradições gerados pela força do desenvolvimento econômico sobre uma região de importância estratégica em relação à metrópole, mas também frágil ambiental e socialmente. Vislumbra-se a intensificação na ocupação industrial e logística ao longo do Arco Metropolitano, da via Dutra e de outros eixos viários intermunicipais de modo predatório e sem atenção às questões socioambientais. Além disso, o risco paira também sobre as encostas e as áreas florestadas próximas à rodovia que poderão abrigar bolsões de miséria. Finalmente, as matrizes reiteram a falta de preocupação da administração pública com o crescimento previsto, prevendo a piora dos problemas de abastecimento e saneamento. 


\section{GT 1 - Desenvolvimento econômico e gestão}

Figura 6 - Mapa produzido pelo GT 1 Desenvolvimento econômico e gestão

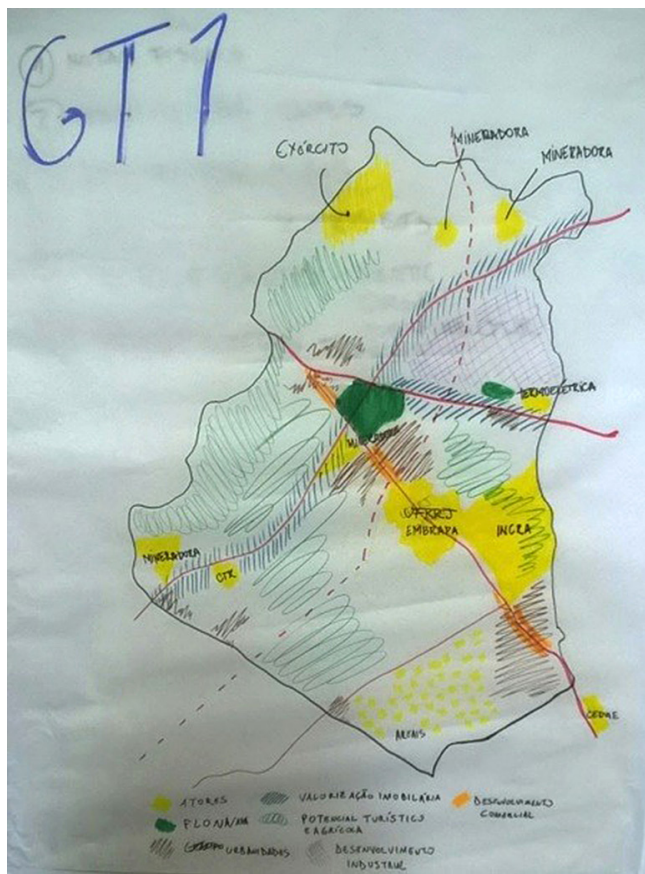

Fonte: acervo Gedur, 2015.
Figura 7 - Mapa do GT 1 digitalizado pela equipe do Gedur

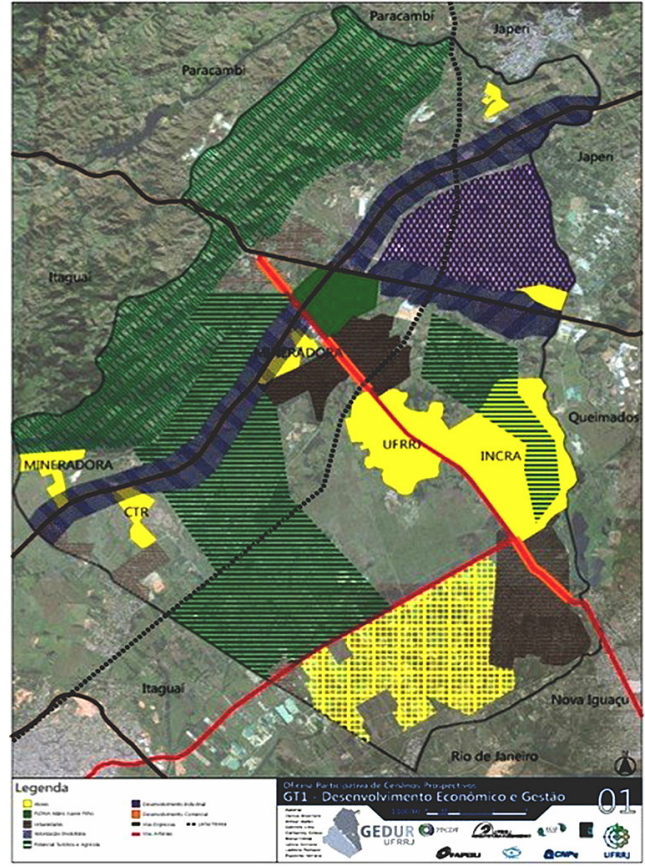

Fonte: acervo Gedur, 2015.

\section{Quadro 1 - Grupo de Trabalho 1 (GT1) - Desenvolvimento econômico e gestão}

\begin{tabular}{|c|c|c|}
\hline $\begin{array}{l}\text { Fatores } \\
\text { internos }\end{array}$ & $\begin{array}{l}\text { POTENCIALIDADES } \\
\text { Potencial turístico; existência de espaços } \\
\text { livres para requalificação de atividades } \\
\text { agrícolas; utilização da linha férrea para } \\
\text { transporte de pessoas }\end{array}$ & $\begin{array}{l}\text { FRAGILIDADES } \\
\text { Infraestrutura limitada; existência de } \\
\text { pedágio intramunicipal; não criação de } \\
\text { instrumentos urbanísticos na forma da lei; } \\
\text { fragmentação urbana e territorial; } \\
\text { desarticulação política institucional dos } \\
\text { municípios da região. }\end{array}$ \\
\hline $\begin{array}{l}\text { OPORTUNIDADES } \\
\text { Geração de trabalho e renda; presença de } \\
\text { atores econômicos estratégicos. }\end{array}$ & $\begin{array}{l}\text { ESTRATÉGIAS OP } \\
\text { Maior oferta de comércio/ serviços. }\end{array}$ & $\begin{array}{l}\text { ESTRATÉGIAS OF } \\
\text { Melhoria da infraestrutura urbana. }\end{array}$ \\
\hline $\begin{array}{l}\text { AMEAÇAS } \\
\text { Instabilidade política; aumento da } \\
\text { criminalidade; crescimento urbano } \\
\text { desordenado; pressão sobre os recursos } \\
\text { ambientais (minério, floresta); } \\
\text { especulação imobilliária e fundiária. }\end{array}$ & $\begin{array}{l}\text { ESTRATÉGIAS AP } \\
\text { Articulação e integração entre academia } \\
\text { e governança pública; maior participação } \\
\text { popular e controle social no planejamento } \\
\text { e gestão. }\end{array}$ & $\begin{array}{l}\text { ESTRATÉGIAS AF } \\
\text { Revisão do PDM; elaboração e aprovação } \\
\text { de legislação específica; gestão sobre } \\
\text { a segurança pública; promoção de } \\
\text { capacitação e oportunidades profissionais } \\
\text { locais; fortalecimento institucional em nível } \\
\text { municipal e intermunicipal. }\end{array}$ \\
\hline
\end{tabular}




\section{GT 2 - Transportes e redes}

\section{Figura 8 - Mapa produzido pelo GT 2 Transportes e redes}

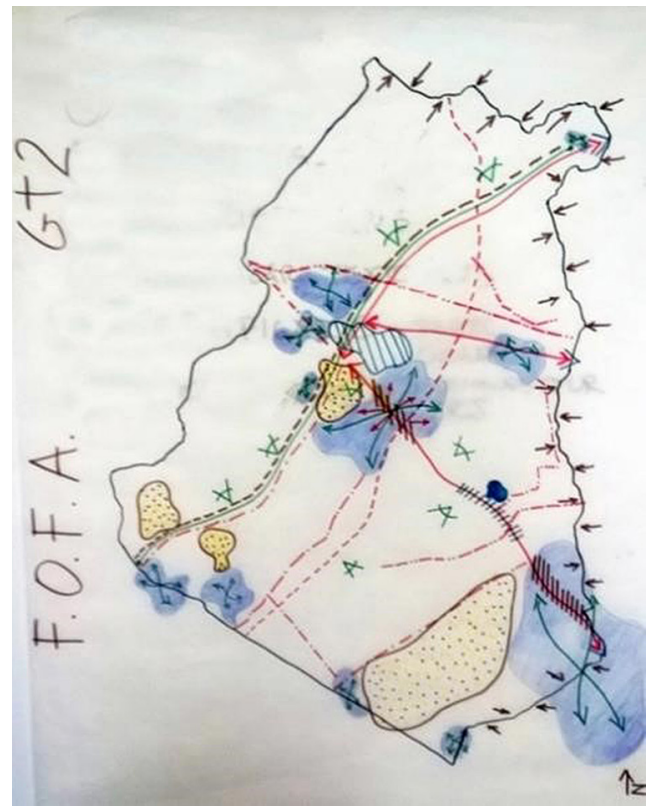

Fonte: acervo Gedur, 2015.

\section{Figura 9-Mapa digitalizado pelo Gedur}

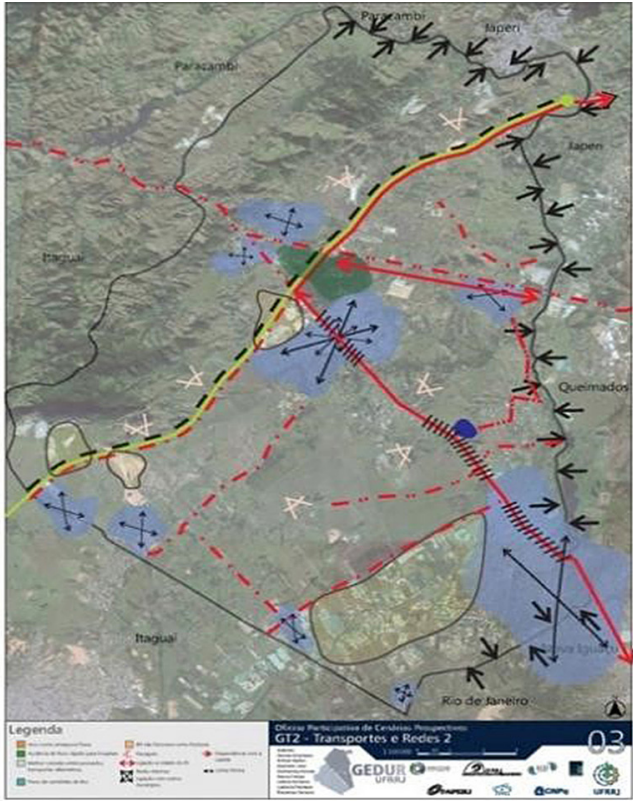

Fonte: acervo Gedur, 2015.

\section{Quadro 2 - Grupo de Trabalho 2 (GT2) - Transportes e redes}

\begin{tabular}{|c|c|c|}
\hline $\begin{array}{l}\text { Fatores } \\
\text { internos }\end{array}$ & $\begin{array}{l}\text { POTENCIALIDADES } \\
\text { Crescimento controlado; adensamento e } \\
\text { compacidade; promoção de transportes } \\
\text { alternativos e ativos; proteção da paisagem } \\
\text { e do ambiente natural; arco como } \\
\text { integração; conexões entre áreas povoadas; } \\
\text { possibilidade de desenvolvimento urbano. }\end{array}$ & $\begin{array}{l}\text { FRAGILIDADES } \\
\text { Falta de planejamento urbano; } \\
\text { dependência do núcleo metropolitano; } \\
\text { monopólio de transportes; unimodal; } \\
\text { locomoção pedonal precária ou inexistente; } \\
\text { fluxo comprometido pela urbanização na } \\
\text { BR-465. }\end{array}$ \\
\hline $\begin{array}{l}\text { OPORTUNIDADES } \\
\text { Ligação com o Rio e outras cidades; } \\
\text { desenvolvimento; turismo; linha férrea / } \\
\text { transporte público; conexões internas nas } \\
\text { cidades; transportes internos. }\end{array}$ & $\begin{array}{l}\text { ESTRATÉGIAS OP } \\
\text { Interligação dos núcleos urbanos (KM49- } \\
\text { KM42); aproveitamento das faixas de redes } \\
\text { de alta tensão para agricultura; uso da linha } \\
\text { férrea como transporte de massa; } \\
\text { municipalização da BR-465. }\end{array}$ & $\begin{array}{l}\text { ESTRATÉGIAS OF } \\
\text { Transporte alternativo entre bairros; } \\
\text { calçadas acessíveis; ciclovias, ciclofaixas ao } \\
\text { longo da BR e nas principais vias; criação de } \\
\text { eixo viário alternativo fora do núcleo. }\end{array}$ \\
\hline $\begin{array}{l}\text { AMEAÇAS } \\
\text { Poluição do ar com fluxo logístico; mão } \\
\text { dupla na BR causa acidentes; fluxo de } \\
\text { caminhões para o CTR; exploração de } \\
\text { recursos naturais queimadas ao longo das } \\
\text { vias poluição, contaminação do rio Guandu } \\
\text { e afluentes; criação de bolsões de pobreza } \\
\text { com a expansão industrial. }\end{array}$ & $\begin{array}{l}\text { ESTRATÉGIAS AP } \\
\text { Mais infraestrutura para as vias já } \\
\text { existentes (piso, iluminação); } \\
\text { melhorias na drenagem pluvial. }\end{array}$ & $\begin{array}{l}\text { ESTRATÉGIAS AF } \\
\text { Criação de estações ferroviárias e } \\
\text { rodoviárias. }\end{array}$ \\
\hline
\end{tabular}




\section{GT 3 - Centralidades urbanas}

Figura 10 - Mapa produzido pelo GT 3 Centralidades urbanas

\section{G3 CENTRALIDADES URBANAS}

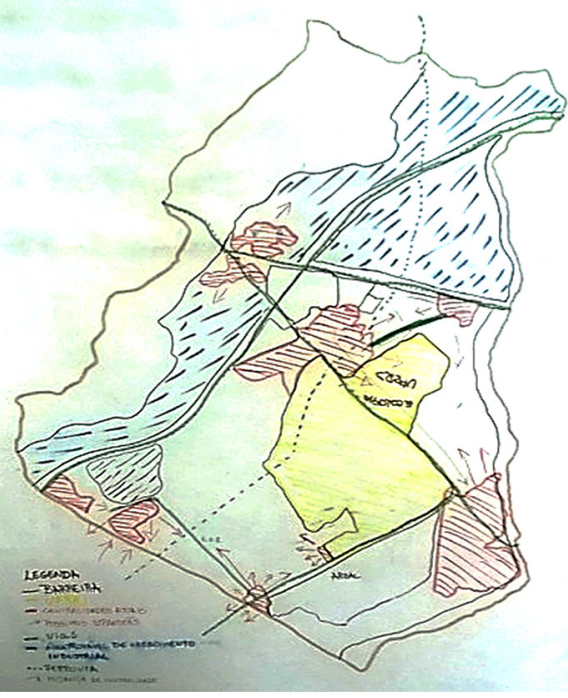

Fonte: acervo Gedur, 2015.
Figura 11 - Mapa digitalizado pelo Gedur

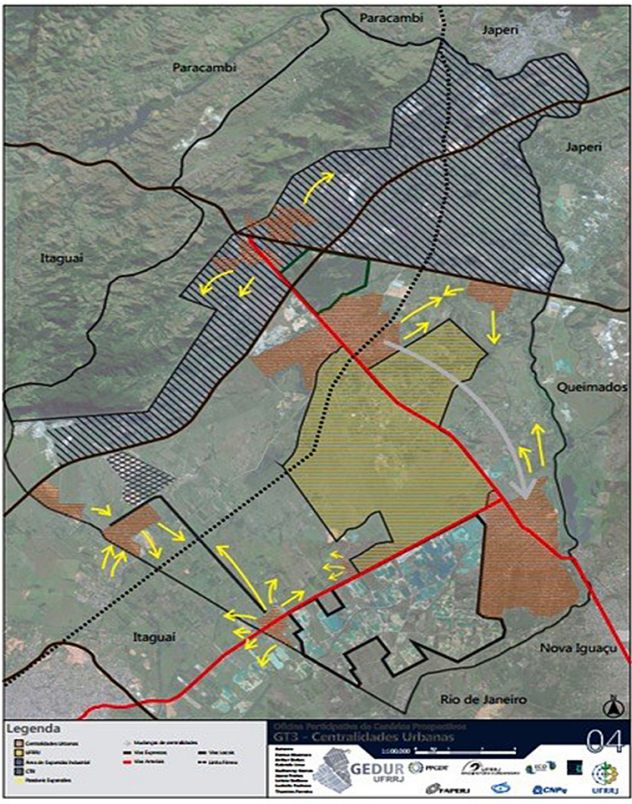

Fonte: acervo Gedur, 2015.

\section{Quadro 3-Grupo de Trabalho 3 (GT3) - Centralidades urbanas}

\begin{tabular}{|c|c|c|}
\hline $\begin{array}{l}\text { Fatores } \\
\text { externos }\end{array}$ & $\begin{array}{l}\text { POTENCIALIDADES } \\
\text { Expansão urbana (Km 49-40, Dutra, Incra, } \\
\text { ecologia; moradias e zona industrial } \\
\text { em Santa Sofia e São Miguel; expansão } \\
\text { urbana ao longo das estradas Santa Rosa e } \\
\text { Piranema; deslocamento do poder público } \\
\text { e serviços do Km } 49 \text { para o Km 40; relação } \\
\text { entre a cidade e a universidade (UFRRJ); } \\
\text { paisagem natural. }\end{array}$ & $\begin{array}{l}\text { FRAGILIDADES } \\
\text { Instalação de empreendimentos de alto } \\
\text { impacto negativo em locais de baixa } \\
\text { resiliência hídrica e topográfica; falta de } \\
\text { controle social para cobrar os benefícios } \\
\text { ou contrapartidas pela instalação dos } \\
\text { empreendimentos que causam impactos } \\
\text { diversos; falta de saneamento, transporte } \\
\text { de massa, infraestrutura e equipamentos } \\
\text { públicos. }\end{array}$ \\
\hline $\begin{array}{l}\text { OPORTUNIDADES } \\
\text { Decorrente da instalação das vias - Arco } \\
\text { Metropolitano e Dutra. }\end{array}$ & $\begin{array}{l}\text { ESTRATÉGIAS OP } \\
\text { Ordenação da ocupação; } \\
\text { requalificação da paisagem local. }\end{array}$ & $\begin{array}{l}\text { ESTRATÉGIAS OF } \\
\text { Restrição da expansão em áreas de risco, de } \\
\text { proteção ambiental e ligadas a atividades } \\
\text { agropastoris. }\end{array}$ \\
\hline $\begin{array}{l}\text { AMEAÇAS } \\
\text { Falta de limite da ocupação de atividades } \\
\text { industriais e mineração extrativa nas } \\
\text { margens do arco e da Dutra; violência } \\
\text { devido à transferência da criminalidade; } \\
\text { clusters de maior poder aquisitivo na } \\
\text { estrada Piranema. }\end{array}$ & $\begin{array}{l}\text { ESTRATÉGIAS AP } \\
\text { Enfoque na resiliência urbana, promovendo } \\
\text { realocação habitacional de áreas de risco; } \\
\text { fiscalização e controle das ocupações ao } \\
\text { longo dos eixos viários. }\end{array}$ & $\begin{array}{l}\text { ESTRATÉGIAS AF } \\
\text { Ampliação da oferta de equipamentos } \\
\text { públicos nos bairros, fortalecendo as } \\
\text { centralidades; promoção de engajamento } \\
\text { popular a partir da atuação e exposição } \\
\text { de estudos e projetos desenvolvidos na } \\
\text { academia. }\end{array}$ \\
\hline
\end{tabular}




\section{GT 4 - Paisagem e planejamento}

Figura 12 - Mapa produzido pelo GT 4 Paisagem e planejamento

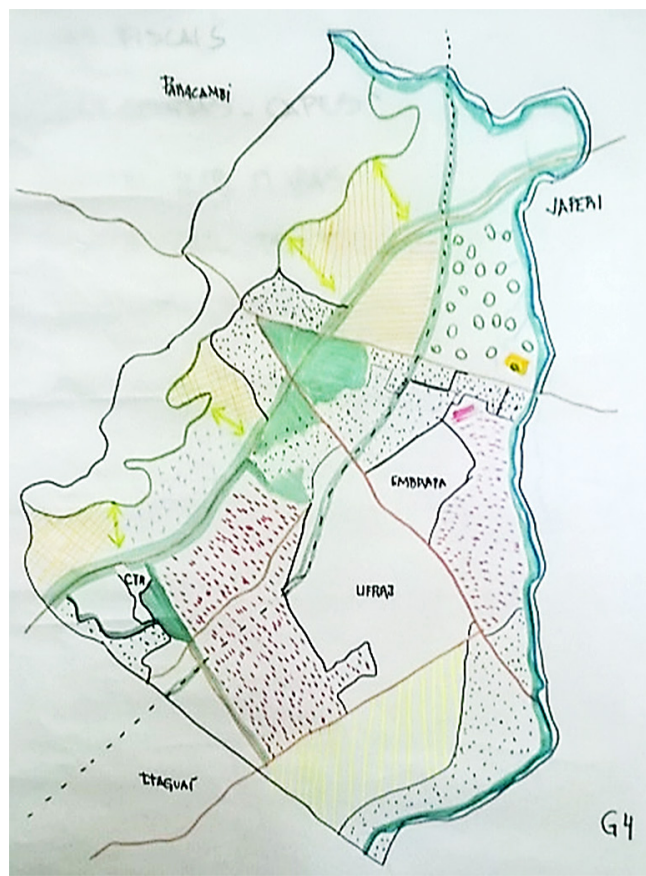

Fonte: acervo Gedur, 2015.
Figura 13 - Mapa digitalizado
pelo Gedur

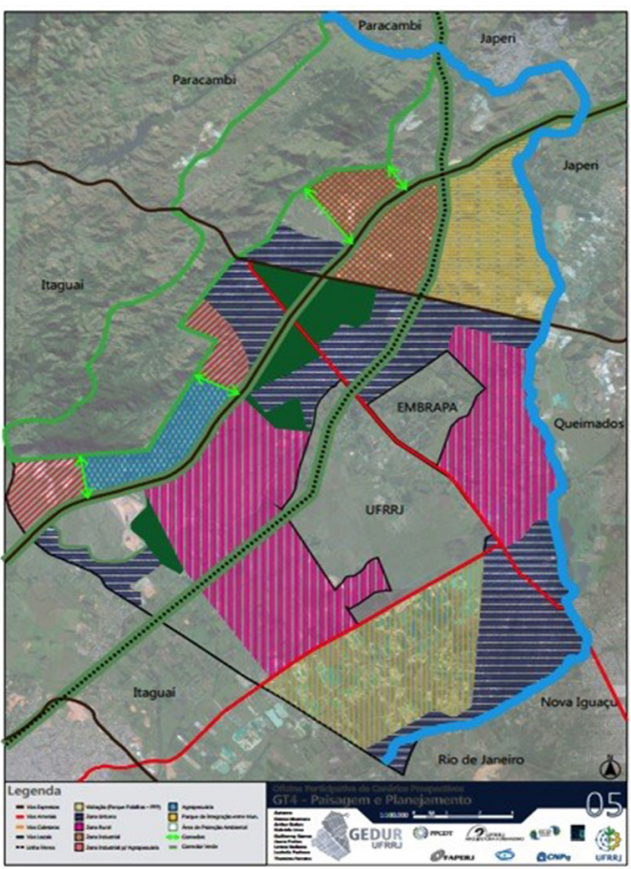

Fonte: acervo Gedur, 2015.

\section{Quadro 4 - Grupo de Trabalho 4 (GT4) - Paisagem e planejamento}

\begin{tabular}{|c|c|c|}
\hline 4 & $\begin{array}{l}\text { POTENCIALIDADES } \\
\text { Expansão da Flona para mineração; } \\
\text { integração do tecido urbano com a Flona; } \\
\text { adensamento do bairro Campo Lindo; } \\
\text { crescimento do Km } 49 \text { em direção a Dutra. }\end{array}$ & $\begin{array}{l}\text { FRAGILIDADES } \\
\text { Possibilidade de invasão do tecido urbano } \\
\text { na área da Floresta Nacional Mário Xavier; } \\
\text { as características rurais e sua produção. }\end{array}$ \\
\hline $\begin{array}{l}\text { OPORTUNIDADES } \\
\text { Potencial turístico da Flona; investimentos } \\
\text { externos. }\end{array}$ & $\begin{array}{l}\text { ESTRATÉGIAS OP } \\
\text { Preservação da Flona; criação de corredores } \\
\text { verdes ao longo do arco, potencializando a } \\
\text { conexão da Flona com a serra; } \\
\text { implementação de novos índices } \\
\text { urbanísticos que permitam o adensamento } \\
\text { urbano. }\end{array}$ & $\begin{array}{l}\text { ESTRATÉGIAS OF } \\
\text { Implementação de parques para uso } \\
\text { público; preservação das características } \\
\text { das zonas rurais; restrição de uso e } \\
\text { parcelamento nas áreas rurais. }\end{array}$ \\
\hline $\begin{array}{l}\text { AMEAÇAS } \\
\text { Tipo de ocupação (adensamento urbano } \\
\text { ao longo do arco); invasão de indústrias na } \\
\text { área rural e ao longo do rio Guandu. }\end{array}$ & $\begin{array}{l}\text { ESTRATÉGIAS AP } \\
\text { Redução ou eliminação da mineração e } \\
\text { apoio a investimentos econômicos menos } \\
\text { danosos ao ambiente ao longo do Arco. }\end{array}$ & $\begin{array}{l}\text { ESTRATÉGIAS AF } \\
\text { Controle de uso do solo; demarcação das } \\
\text { APPs e programas de preservação dessas } \\
\text { áreas. }\end{array}$ \\
\hline
\end{tabular}


Alguns exemplos dos cenários prospectados a partir dos resultados aferidos na Oficina Participativa são oferecidos a seguir.

Cenário 1 - 0 irreversível processo de crescimento demográfico metropolitano alavancado pelos projetos de investimentos atrai um contingente populacional para os territórios periféricos em busca de emprego, renda e baixo custo de moradia. Serão os ocupantes dos empreendimentos imobiliários de baixa renda implantados nos ditos "vazios urbanos", tais como os empreendimentos do PMCMV para a Faixa 1, ou ocuparão os espaços livres de edificações, formal ou informalmente, como historicamente acontece nas periferias metropolitanas (Maricato, 2001). A produção de novos bolsões de miséria e ocupações irregulares ao longo das rodovias, nas margens dos rios e córregos (APPs) e nas encostas, sem uma devida atenção dos órgãos públicos de planejamento e ordenamento territorial ou políticas públicas habitacionais em nível municipal, torna-se, assim, uma ameaça real. Como estratégia de ação, sugerem-se o adensamento das áreas urbanizadas e a melhoria da infraestrutura instalada, além da criação de parques lineares tratados paisagisticamente, arborizados e acessíveis ao público em geral, de modo a estabelecer vínculos dos moradores com o lugar, e promovendo a criação de corredores verdes, entre outros benefícios urbanísticos e ambientais.

Cenário 2 - Em nível local, a urbanização precária e sem qualidade, tanto nos núcleos mais populosos, quanto nas áreas periurbanas em consolidação, apresenta problemas urbanos e infraestruturais, tais como: controle de tráfego e sinalização inadequados; iluminação pública inexistente ou ineficiente; pavimentação das vias deficiente ou inadequada; precariedade de calçamento dos passeios; falta de acessibilidade universal; drenagem pluvial e saneamento básico inexistentes; ocupação dos lotes irregulares; apropriação informal ou ilegal de espaços públicos, etc. Em ação recente do governo estadual, alguns bairros periféricos tiveram suas vias asfaltadas, porém sem quaisquer outras melhorias públicas complementares e necessárias, tais como drenagem pluvial e acessibilidade, gerando transtornos de mobilidade e acessibilidade urbana. Como estratégia, são sugeridos exemplos de melhores práticas de drenagem pluvial urbana, bem como reconfiguração dos espaços livres públicos sub ou mal utilizados ou sem tratamento urbanístico, representados por largos, praças e estacionamentos ao longo do eixo da BR-465.

Cenário 3 - As centralidades inter e intraurbanas são segregadas pelas rodovias e ferrovia que cortam o município, bem como por grandes áreas ocupadas institucionalmente (UFRRJ, Embrapa, Emater), este configurando como um ponto crítico na articulação entre a governança municipal e a academia, dado que limita a expansão urbana e a conectividade do território. Alguns bairros mais distantes no lado norte da via Dutra sequer são atendidos por transporte público. Estratégia: promover o adensamento dos núcleos urbanizados com a promoção de serviços e equipamentos públicos educacionais e de capacitação e de melhorias urbanísticas, conectando-os por meio de transporte público de baixo consumo de energia, ciclovias e ciclofaixas, na perspectiva do desenvolvimento orientado pelo transporte (TOD).

A grande quantidade de informações qualitativas e quantitativas produzidas pelos distintos métodos de prospecção é tratada analiticamente de modo a retratar a riqueza 
e a complexidade de futuros possíveis e possibilita traçar cenários antecipando algumas saídas e "hipóteses alternativas sobre o futuro", conhecer melhor a realidade e "proporcionar a melhor política ou o suporte à decisão", evitando-se surpresas, adaptando-se e agindo efetivamente (Santos, 2013, pp. 19-21).

\section{Considerações finais}

O presente artigo apresentou a aplicação de uma atividade de extensão universitária inspirada na cartografia social, a Oficina Participativa de Construção de Cenários Prospectivos, buscando reafirmar a importância da metodologia de prospecção de cenários a partir de processos participativos de cartografia social e da investigação multitemática e transescalar para a definição de diretrizes para a elaboração de políticas públicas.

A Oficina Participativa buscou estabelecer estratégias de desenvolvimento socioeconômico aliado ao planejamento sustentável. A prospecção por cenários e a análise Swot, adaptados e ressignificados para a aplicação na rica atividade de extensão, favoreceram a reflexão coletiva, organizada e otimizada, sobre tendências e potenciais de desenvolvimentos para a solução de questões-chave e eventos incertos e para antever resultados futuros que possam impactar positivamente o planejamento territorial. A reflexão coletiva possibilitou identificar, espacializar e cartografar as potencialidades, fragilidades e conflitos territoriais; prospectar cenários e simular vetores de crescimento, manchas de uso e ocupação; bem como identificar e delimitar potenciais corredores verdes e áreas a serem preservadas ou recuperadas.
A baixada de Sepetiba e, em especial, o município de Seropédica, o objeto em estudo, configuram-se como um verdadeiro laboratório de pesquisa, cujos problemas comuns e as carências infraestruturais e socioambientais são passíveis de serem revertidos com a aplicação eficiente e eficaz de políticas públicas equilibradas e justas, construídas democraticamente por meio de processos participativos. Este é um dos mais relevantes aspectos apresentados neste trabalho: a possibilidade de inserção social e a participação democrática nos processos de planejamento e gestão do território.

Em todas as etapas de desenvolvimento da pesquisa, bem como na Oficina realizada, buscou-se o equacionamento dos conflitos e desequilíbrios entre as forças corporativas e as redes ambientais e comunitárias. 0 fortalecimento do controle social sobre o uso e a ocupação do solo bem como o envolvimento da população sobre ações e políticas públicas tornam-se elementos-chave para reverter o cenário de contínua degradação socioambiental e esgotamento de recursos, verificado em Seropédica. Entretanto, uma das principais limitações encontradas foi o envolvimento da administração pública municipal, tanto na atividade, como no pensar coletivo sobre os desígnios daquele território, o que ratifica fragilidade na relação entre a gestão pública e a participação social.

Finalmente, a despeito das limitações encontradas, reiteramos que a rica experiência participativa favoreceu um fórum coletivo, diversificado, inclusivo e democrático de debate e coleta de dados e informações relevantes sobre o território. Atuando como ponte entre gestão municipal e coletividade, acreditamos ser a ferramenta Oficina 
Participativa, como atividade de extensão universitária, um importante auxiliar na propagação e no intercâmbio do conhecimento específico na área do planejamento urbano com vistas ao desenvolvimento sustentável, justo e equilibrado.

\section{[I] http://orcid.org/0000-0002-6482-0943 XVII}

Universidade Federal Rural do Rio de Janeiro, Departamento de Arquitetura e Urbanismo, Programa de Pós-Graduação em Desenvolvimento Territorial e Políticas Públicas. Seropédica, RJ/Brasil.

denisedealcantara@gmail.com

\section{Agradecimentos}

O presente trabalho foi realizado com apoio da Coordenação de Aperfeiçoamento de Pessoal de Nível Superior - Brasil (Capes), Código de Financiamento 001, e patrocinado com Auxílio à Pesquisa Básica (APQ-1-Faperj), Apoio a Eventos (Paep-Capes e APQ-2-Faperj) e na concessão de bolsas de Iniciação Científica para graduandos e voluntários que participaram ativamente da pesquisa, nomeadamente: Arthur S. B. dos Santos, Gabriela M. Lima, Guilhermy G. P. dos Santos, Joana Freitas e Ludmila P. Erthal.

\section{Notas}

(1) Cf. site do Ministério do Planejamento, disponível em: http://www.pac.gov.br/noticia/68777baf. Acesso em: 13 set 2019.

(2) Rede de Pesquisa Quapá-SEL - Quadro do Paisagismo no Brasil, Faculdade de Arquitetura e Urbanismo da Universidade de São Paulo; SELRJ - Sistema de Espaços Livres do Rio de Janeiro, Universidade Federal do Rio de Janeiro; Gedur - Grupo de Pesquisa em Transformação de Uso, Ocupação e Desenvolvimento Urbano e Regional, da Universidade Federal Rural do Rio de Janeiro.

(3) Contemplada com auxílios da Faperj APQ-2 2015/1 - Proc. n. E-26/010.000.492/2015) e Paep Capes (Auxpe-Paep-1304/2015), além do apoio institucional do PROPPG; Proext; PPGDT; DAU-IT, da UFRRJ; e do grupo SELRJ/UFRJ.

(4) A pesquisa Morfologia da paisagem e transformação de usos: análise, categorização e construção de cenários prospectivos do sistema de espaços livres de Seropédica foi patrocinada com Auxílio à Pesquisa Básica Faperj (APQ-1 - Proc. n. E-26-110.397/2014). A Oficina Participativa foi patrocinada com recursos Faperj (APQ-2 - Proc. E-26-10.000492/2015) e Capes (Processo Paep 3105/201583). 
(5) Ver mapa com a configuração da RMRJ atualizada em 2018 em Fundação CEPERJ - Centro Estadual de Estatísticas, Pesquisa e Formação do Estado do Rio de Janeiro. Disponível em http:// www.ceperj.rj.gov.br/Conteudo.asp?ident=79

(6) Fontes de consulta: Google Earth, IBGE, Ceperj, SELRJ-Proarq-FAU/UFRJ, Plano Diretor do Município de Seropédica (PDM), Cedae-RJ e bases cadastrais disponibilizadas pelo Departamento de Agrimensura da UFRRJ e Comitê Guandu.

(7) Na mesa de abertura do evento e nas mesas-redondas, estiveram presentes a convite da organização o então subsecretário de urbanismo de Seropédica, acompanhado de técnicas da prefeitura que contribuíram com a visão da governança pública.

(8) A tradução de Swot (Strenghts-Weakenesses-Opportunities-Threats) para o português resulta na sigla Fofa (Fortalezas-Oportunidades-Fraquezas-Ameaças). Disponível em: http://www.portaladministracao.com/2014/01/analise-swot-conceito-e-aplicacao.htm. Acesso em: 26 jun 2016.

\section{Referências}

ACSELRAD, H. (org.). (2010). Cartografias sociais e dinâmicas territoriais: marcos para o debate. Rio de Janeiro, UFRRJ, Ippur.

ALCANTARA, D. (2016). Conflitos socioambientais e o periurbano na baixada de Sepetiba: nós nas redes, redes sem nós. Recôncavo - Revista de História da Uniabeu. Duque de Caxias, A. Marques. e Uniabeu.

ALCANTARA, D. e SCHUELER, A. (2015). Gestão das Águas e Sustentabilidade: desafios globais e respostas locais a partir do caso de Seropédica, na Região Metropolitana do Rio de Janeiro. Cadernos Metrópole. São Paulo, v. 17, n. 33, pp. 109-126.

BRANDÃO, C. (2012). Território e desenvolvimento - as múltiplas escalas entre o local e o global. Campinas, Editora da Unicamp.

CARDOSO, A. e ARAÚJO, F. (2012). "A via expressa das políticas públicas no Rio de Janeiro: reflexões acerca dos impactos do Arco Metropolitano". In: OLIVEIRA et al. (orgs.). Grandes projetos metropolitanos - Rio de Janeiro e Belo Horizonte. Rio de Janeiro, Letra Capital.

CICCOLELLA, P. (2014). Metrópolis Latinoamericanas - Más allá de la globalización. Ciudad Autónoma de Buenos Aires, Café de las Ciudades.

FORMAN, R. (2008). Urban regions - Ecology and planning beyond the city. Cambridge, Cambridge University Press

GOVERNO DO ESTADO (s/d). Plano Estratégico de Desenvolvimento Urbano Integrado da Região Metropolitana do Rio de Janeiro - Tomo II. Disponível em: https://www.modelarametropole. com.br/wp-content/uploads/2018/09/Produto-18_Tomo-2-1.pdf.

HARVEY, D. (2011). O enigma do capital e as crises do capitalismo. São Paulo, Boitempo Editorial.

IBGE - Instituto Brasileiro de Geografia e Estatística (2019). Cidades@. Disponível em https://cidades. ibge.gov.br/brasil/rj/seropedica/panorama. Acesso em: 24/09/2019 
ISIDORO, I.; ALCANTARA, D. e TÂNGARI, V. (2011). Uma inovação metodológica no estudo das unidades de paisagem: as oficinas locais nos municípios influenciados pelo arco metropolitano. In: Colóquio Quapá-SEL. São Paulo: FAUUSP. Disponível em: http://quapa.fau.usp.br/wordpress/ wp-content/uploads/2016/03/Uma-inova\%C3\%A7\%C3\%A3o-metodol\%C3\%B3gica-no-estudodas-unidades-de-paisagem-As-Oficinas-Locais-nos-munic\%C3\%ADpios-influenciados-pelo-ArcoMetropolitano.pdf. Acesso em: 1ㅇ jun 2019.

KZURE-CERQUERA, H. (2014). "A saúde da cidade sob suspeita”. In: SILVEIRA, C.; FERNANDES. T.M. e PELLEGRINI, B. (orgs.). Cidades saudáveis? Alguns olhares sobre o tema. Rio de Janeiro, Fiocruz.

MAGNOLI, M. (2006). Em busca de outros espaços livres de edificação. Revista Paisagem e Ambiente Ensaios. São Paulo, FAUUSP, n. 21, pp. 143-173.

MARICATO, E. (2001). Brasil, cidades - alternativas para a crise urbana. Petrópolis/RJ, Vozes.

McHARG, I. (1992). Design with Nature. Nova York, Wiley.

MONTEZUMA, R. e CINTRA, D. (2012). “O arco metropolitano do Rio de Janeiro: um marco na transformação da paisagem metropolitana”. In: TÂNGARI, V.; REGO, A. e MONTEZUMA, R. (orgs.). O Arco Metropolitano do Rio de Janeiro: integração e fragmentação da paisagem metropolitana e dos sistemas de espaços livres de edificação. Rio de Janeiro, Proarq-FAU-UFRJ.

NOVA CEDAE (2015). Projeto básico do esgotamento sanitário da bacia hidrográfica do Rio Guandu - lote 2. Relatório do projeto básico de Seropédica. Rede coletora de esgoto. Encibra, Cohidro.

OBSERVATÓRIO DAS METRÓPOLES (2005). Como andam as metrópoles - Relatório final. Rio de Janeiro, Ippur/UFRJ. Disponível em: http://www.observatoriodasmetropoles.ufrj.br/como_anda/como_ anda_RM_riodejaneiro.pdf. Acesso em: 13 jun 2019.

OLIVEIRA, F.: CARDOSO, A.; COSTA, H. e VAINER, C. (2012). Grandes projetos metropolitanos: Rio de Janeiro e Belo Horizonte. Rio de Janeiro, Letra Capital.

PICKTON, D. e WRIGHT, S. (1998). What is SWOT in Strategic Analysis? Strategic Change, v. 7, n. 2, pp. 101-109. Wiley \& Sons. Disponível em: https://www.researchgate.net/publication/246915222 What's_SWOT_in_strategic_analysis. Acesso em: 14 jun 2016.

PNUD (2013). Atlas do Desenvolvimento Humano do Brasil. Disponível em: http://www.atlasbrasil.org. br/2013/pt/. Acesso em: 24 set 2019.

REGO, A. (2011). O arco metropolitano e prospecções sobre as centralidades urbanas da Região Metropolitana do Estado do Rio de Janeiro. In: XIV ENANPUR. Anais...Rio de Janeiro, Anpur.

RUBEM, A. e MOURA, A. (2014). Cenários prospectivos no apoio à decisão: uma proposta de aprimoramento do método de Schoemaker. Relatórios de Pesquisa em Engenharia de Produção v. 14, n. B5, pp. 70-80. Disponível em: http://www.producao.uff.br/images/RPEP_B5.pdf. Acesso em: 14 junho 2019.

SACK, R. (2011). “O significado de territorialidade”. In: DIAS, L. e FERRARI, M. (orgs.). Territorialidades humanas e redes sociais. Florianópolis, Insular.

SANTOS, M. (2006). A natureza do espaço: técnica e tempo, razão e emoção. São Paulo, Editora da Universidade de São Paulo.

(2013). O planeamento por cenários como resposta das organizações a desafios colocados na época atual. Disponível em: http://home.uevora.pt/ mosantos/download/ PlaneamentoporCenarios_01Jun13.pdf. Acesso em: 15 jun 2019. 
SANTOS JUNIOR, O. e MONTANDON D. (orgs.) (2011). Os planos diretores municipais pós-estatuto da cidade: balanço crítico e perspectivas. Rio de Janeiro, Letra Capital, Observatório das Cidades e Ippur/UFRJ. Disponível em: http://observatoriodasmetropoles.net.br/arquivos/biblioteca/ abook_file/plano_diretor.pdf. Acesso em: 15 jun 2019.

SCHOEMAKER, P. J. H. (1995). Scenario planning: a tool for strategic thinking. MIT Sloan Management Review, v. 36, n. 2, pp. 25-40.

SEBRAE (2015). Painel regional: Baixada Fluminense. Observatório Sebrae/RJ. Rio de Janeiro, Sebrae. Disponível em: http://www.sebrae.com.br/Sebrae/Portal\%20Sebrae/UFs/RJ/Anexos/Sebrae_ INFREG_2014_BaixadaFlum.pdf. Acesso em: 24 set 2019.

SEROPÉDICA (2006). Plano Diretor Participativo do Município de Seropédica. Lei n. 328 de 2006. Prefeitura Municipal de Seropédica.

SILVA, R. D. (2017). "Royalties e desenvolvimento regional: uma reflexão sobre os desafios do Rio De Janeiro". In: MONTEIRO NETO, A.; CASTRO, C. N. e BRANDÃO, C. A. (orgs.) Desenvolvimento regional no Brasil: políticas, estratégias e perspectivas. Rio de Janeiro, Ipea.

SILVA, J.; LIMA, F. e MAGALHÃES, N. (2015). Aplicação do conceito de unidade morfoterritorial na escalas metropolitana, intraurbana e local. Revista de Morfologia Urbana, v. 3, n. 2, pp. 105-120. Disponível em: http://revistademorfologiaurbana.org/index.php/rmu/article/view/12. Acesso em: 10 jun 2019.

SOUZA, M. J. N. (2012). "Arco Metropolitano - integração ou fragmentação? Considerações a partir do exemplo de Nova Iguaçu". In: TÂNGARI, V.; REGO, A. Q. e MONTEZUMA, R.C. (orgs.). O arco metropolitano do Rio de Janeiro: integração e fragmentação da paisagem metropolitana e dos sistemas de espaços livres de edificação. Rio de Janeiro, Proarq-FAU-UFRJ.

TÂNGARI, V.; SCHLEE M. e ANDRADE, R. (orgs.) (2009). Sistema de espaços livres - o cotidiano, apropriações e ausências. Rio de Janeiro, FAU/UFRJ-Proarq.

TÂNGARI, V.; REGO, A. e MONTEZUMA, R. (orgs.) (2012). Arco Metropolitano do Rio de Janeiro: integração e fragmentação da paisagem metropolitana e dos sistemas de espaços livres de edificação. Rio de Janeiro, Proarq-FAU-UFRJ.

(2013). O Arco Metropolitano do Rio de Janeiro: debates e reflexões. Rio de Janeiro, PROARQFAU-UFRJ (CD-ROM).

TCE - Tribunal de Contas do Estado (2017). Estudos socioeconômicos dos municípios do Estado do Rio de Janeiro - Seropédica. Disponível em https://www.tce.rj.gov.br/estudos-socioeconomicos1. Acesso em: 24 set 2019.

VIANNA, M. A. (2017). A agricultura familiar em Seropédica, RJ: gestão social, participação e articulação dos atores do polo de conhecimento local em agropecuária. Tese de Doutorado. Seropédica, Universidade Federal Rural do Rio de Janeiro.

VILLELA, L. E. (2013). “Redes, desenvolvimento e gestão social em Arranjos Produtivos Locais (APLs) no estado do Rio de Janeiro". In: TENÓRIO, F. G. (org.). Gestão social e gestão estratégica. Rio de Janeiro, FGV. 
